\title{
Analisis 7S McKinsey PT Hasil Rotibua Abadi untuk Perbaikan Organisasi
}

\author{
Rydho Jalu Nuringtyas \\ Universitas Airlangga \\ rydhojalu@gmail.com
}

\begin{abstract}
This study aims to identify and find solutions to delay construction work happening on the SCE project. The SCE project is a school building construction project. The background of this study is due to indications of delay with a difference of $25 \%$ between the schedule plan and the reality in the ground. The factors that cause the delay must be well identified so that a larger delay can be avoided and can provide solutions to these problems. From the results of Fishbone analysis and AHP, 11 factors were found to influence the delay in SCE project.
\end{abstract}

Keywords: operational management, project, delay

\section{PENDAHULUAN}

Coating merupakan salah satu bidang pekerjaan dalam pemeliharaan suatu pabrik, tujuan dari coating ini sendiri merupakan pelapisan dengan menggunakan bahan kimia maupun cat untuk menghambat laju korosi suatu mesin maupun struktur baja suatu pabrik, Dalam lini usaha bidang konstruksi khususnya pelapisan anti karat (coating) pada umumnya masuk dalam kategori bidang konstruksi kecil maupun menengah. Menurut Kepmenaker RI No. 91 Tahun 2016, atas arahan Dirjen IATT Kementerian Perindustrian maka Asosiasi Coating Indonesia (Ascoatindo) mengajak seluruh stakeholder Coating untuk mendukung dan memberikan contractor terhadap program pemerintah ini dan pada tahun 2007 SKKNI Sektor Industri Jasa Pengolahan Sub-Sektor Industri Jasa Pelapisan Bidang Coating Sub-bidang Proteksi mengesahkan Coating sebagai salah satu jasa konstruksi sub-bidang proteksi melalui Keputusan Menakertrans No. 102/MEN/II/2007.

Beberapa peta persaingan pada industri Coating dalam skala nasional adalah PT Surya Pranusa, PT Nuscaco Anti-Corrosion Indonesia, PT Indopama Karya Perkasa, dan PT Her- mon Pancakarsa Libratama. Keempat perusahaan tersebut dianggap sebagai pesaing utama karena memiliki keunggulan terkait dengan sisi harga yang lebih murah saat pelelangan dalam beberapa bidang coating. Berikut merupakan penjelasan keunggulan dan kelemahan beberapa kompetitor pada bidang coating termasuk PT Hasil Rotibua Abadi.
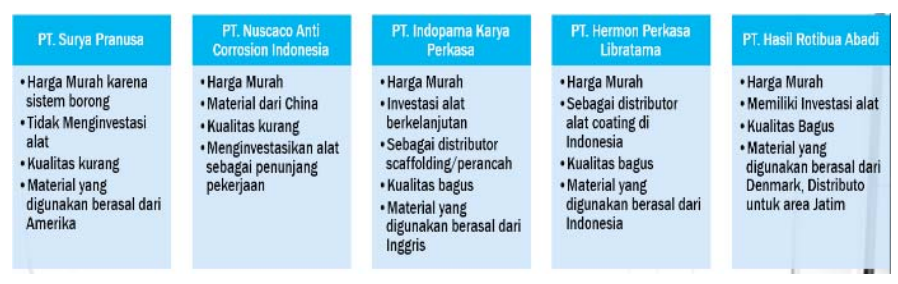

Gambar 1.1 Keunggulan dan Kelemahan Beberapa Kompetitor Bidang Coating

Beberapa pesaing ini umumnya menerapkan harga produk jasa yang lebih rendah daripada harga produk jasa kompetitornya untuk ditawarkan kepada pihak user. Salah satu faktor yang menyebabkan harga pesaing lebih rendah adalah perusahaan pesaing, sebagai contoh PT Indopama Karya Perkasa memiliki aset penunjang jasa yang akan ditawarkan seperti memiliki investasi pada perancah/scaffolding untuk pekerjaan yang khususnya berkaitan dengan ketinggian, sehingga 


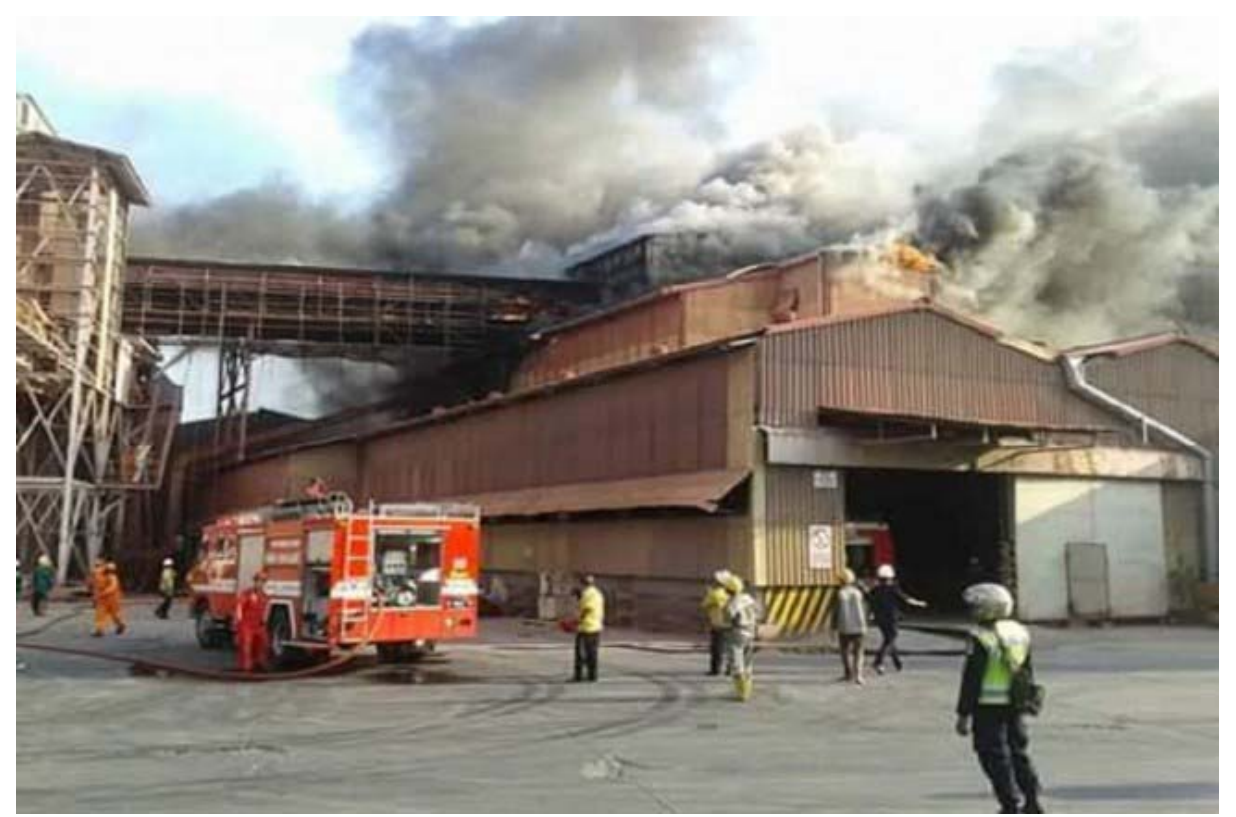

Gambar 1.2 Lokasi Kecelakaan Kerja di Area PT Petrokimia Gresik Sumber: http://jatim.metrotvnews.com

pada saat lelang dapat memberi penawaran harga lebih rendah. Selain itu dengan perusahaan menginvestasikan alat-alat utama penunjang proses jasa pekerjaan seperti apa yang PT Hasil Rotibua Abadi dapat menurunkan biaya rancangan suatu proyek karena biasanya banyak perusahaan hanya menyewa alat utama pada proses jasa tersebut, apabila ada keterlambatan pekerjaan maka biaya akan membengkak dua kali lipat meskipun produk yang digunakan berasal dari Denmark.

PT Hasil Rotibua Abadi adalah salah satu perusahaan yang bergerak di bidang operating and maintenance sub bidang pelapisan anti korosi atau biasa disebut coating service. Perusahaan tersebut memiliki lokasi kantor maupun workshop di Gresik. Target konsumen dari PT Hasil Rotibua Abadi adalah perusahaan-perusahaan BUMN yakni PT PJB dan PT Petrokimia Gresik, di mana para konsumen tersebut membutuhkan pemeliharaan atas aset penunjang produksi yang mereka miliki seperti contoh internal tank corrosion, structure conveyor.
Pada tahun 2015, PT Hasil Rotibua Abadi mengalami permasalahan yang rumit yakni terjadinya kecelakaan kerja yang mengakibatkan suatu material berjalan (conveyor) pada area NPK pabrik 2 PT Petrokimia Gresik terbakar habis hingga menyisakan puing struktur dan material berjalan.

Berdasarkan ilustrasi proses safety management yang dilakukan oleh PT Petrokimia terhadap para pekerja PT Hasil Rotibua Abadi, terdapat salah satu kelalaian pekerja dalam proses pengendalian K3 yakni pada saat pengelasan di atas ketinggian lebih dari tujuh meter para pekerja tidak melindungi percikan api pengelasan dengan air maupun dengan penutup area yang kontak dengan percikan api. Karena itu, api menyambar langsung kepada atap yang terbuat dari plastik dan api langsung menyambar sangat cepat hingga membuat area conveyor PT Petrokimia Gresik terbakar habis.

Dari pemaparan di atas, PT Hasil Rotibua Abadi saat ini memang hanya menerapkan stra- 
tegi bisnis yang belum terstruktur dan belum menerapkan strategi yang sesuai dengan ketentuan SMK3 dan penerapan strategi internal yang berbasis pada data analisis.

Dengan terjadinya kecelakaan kerja maupun hal yang mengakibatkan kerugian pada perusahaan, PT Hasil Rotibua Abadi saat ini terkena dampak negatif yakni penurunan pada nilai ROA maupun ROE merupakan salah satu dampaknya karena akibat dari kecelakaan kerja tersebut perusahaan harus membayar denda akibat kecelakaan maupun di-blacklist dari PT Pupuk Indonesia Holding Company untuk tidak diperbolehkan bekerja di area tersebut selama 2 tahun hingga 2017. Berikut data ROA dan ROE pada data yang disajikan pada tabel berikut.

Tabel 1 ROE dan ROA PT Hasil Rotibua Abadi Tiga Tahun Terakhir

\begin{tabular}{|c|c|c|c|c|c|c|}
\hline Tahun & & BA BERSIH & TOTAL EKUITAS & TOTAL ASET & ROE & ROA \\
\hline 2014 & $\mathrm{Rp}$ & $150,576,594$ & $\begin{array}{ll}\operatorname{Rp} & 2,250,366,376\end{array}$ & $\operatorname{Rp} 1,905,962,396$ & $6.69 \%$ & $7.90 \%$ \\
\hline 2015 & $\mathrm{Rp}$ & $92,413,747$ & $\begin{array}{ll}\mathrm{Rp} & 1,998,376,142\end{array}$ & $\operatorname{Rp} 2,649,062,440$ & $4.62 \%$ & $3.50 \%$ \\
\hline 2016 & $\mathrm{Rp}$ & $68,197,091$ & $\begin{array}{ll}\mathrm{Rp} & 1,898,376,143\end{array}$ & Rp $2,066,573,234$ & $3.6 \%$ & $3.30 \%$ \\
\hline
\end{tabular}

Berdasarkan pemaparan tabel di atas dapat disimpulkan bahwa terdapat penurunan ROE maupun ROA dalam tiga tahun terakhir menurun sekitar $+/-3 \%$. ROA maupun ROE menurun ini dikarenakan pendapatan pada tiga tahun terakhir yang menurun secara signifikan, berikut merupakan grafik pada pendapatan PT Hasil Rotibua Abadi dalam tiga tahun terakhir.

Pada pemaparan grafik pendapatan PT Hasil Rotibua Abadi tiga tahun terakhir terhitung mulai 2014 hingga 2016 ini terjadi penurunan secara beruntun. Pada 2014, PT Hasil Rotibua Abadi sedang mendapatkan pendapatan paling besar sekitar Rp 5.323.942.381 tetapi pada saat tahun 2015 berjalan pendapatan perusahaan menurun sebesar 15\% dengan jumlah Rp 4.505.661.823.

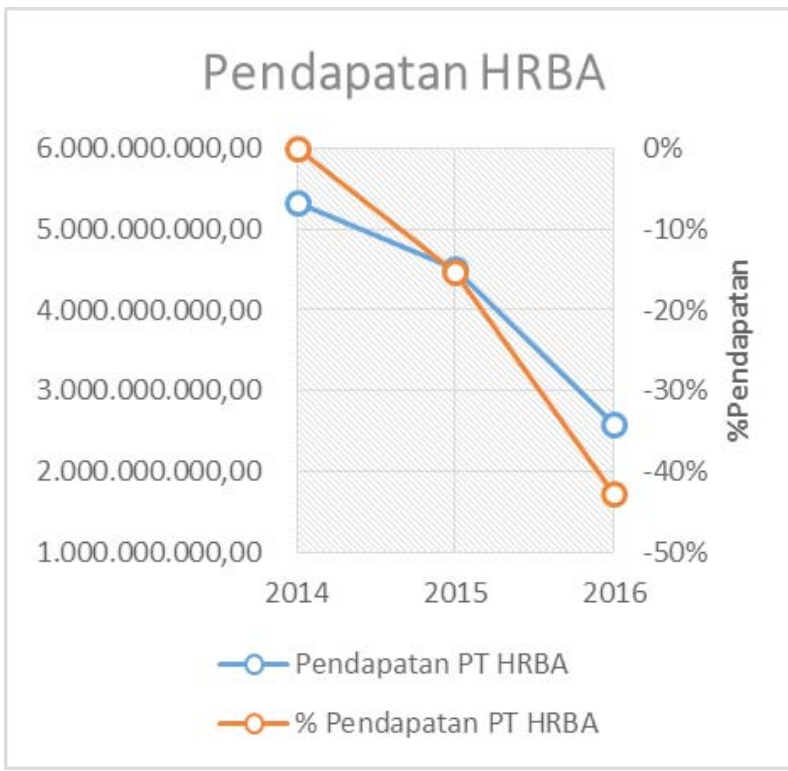

Gambar 1.1 Grafik Pendapatan PT Hasil Rotibua Abadi Tiga Tahun

Untuk mengetahui bagaimana cara peningkatan performa maupun metode bisnis proses yang sesuai dengan aktivitas PT. Hasil Rotibua Abadi, peneliti ingin menggunakan framework 7S McKinsey, dengan menggunakan analisis ini diharapkan dapat memperbaiki kondisi internal perusahaan dan mengetahui bisnis proses yang sesuai dengan visi perusahaan agar meningkatkan performa maupun dalam perbaikan perusahaan.

\section{TINJAUAN PUSTAKA}

\section{Strategi}

Menurut David (2011) Strategi adalah sarana bersama dengan tujuan jangka panjang yang hendak dicapai. Strategi bisnis mencakup ekspansi geografis, diversifikasi, akuisisi, pengembangan produk, penetrasi pasar, pengetatan, divestasi, likuidasi, dan usaha patungan atau joint venture. Strategi adalah aksi potensial yang membutuhkan keputusan manajemen puncak dan sumber daya perusahaan dalam jumlah besar. Jadi strategi adalah sebuah tindakan aksi atau 
kegiatan yang dilakukan oleh seseorang atau perusahaan untuk mencapai sasaran atau tujuan yang telah ditetapkan.

\section{Analisis 7S McKinsey}

Berdasarkan pernyataan Peters dan Waterman (2004), yang menjelaskan dua hal yang sama dengan pengembangan organisasi (organization development). Pertama, mengasumsikan adanya sebuah bentuk organisasi yang ideal dan menjelaskannya secara terperinci. Kedua, nilainilai humanisme yang begitu penting dalam pengembangan organisasi yang tersirat dalam bentuk organisasi yang diusulkan oleh Peters dan Waterman. Akan tetapi, alat analisis yang dikembangkan oleh para penulis inilah yang paling relevan untuk pembangunan organisasi karena alat itu menggambarkan sifat dasar pengembangan organisasi. Alat analisis itu merupakan $7 \mathrm{~S}$ McKinsey. Menurut Sikka et al. (2005) menyatakan bahwa implementasi yang efektif pada penggunaan semua metode ini tidak tergantung pada peningkatan kesadaran akan potensi, tetapi juga tentang meningkatkan kompetensi orang yang bersangkutan.

\section{METODE PENELITIAN}

Pada penelitian kali ini pengumpulan data menggunakan survey untuk menghasilkan data primer. Survei adalah teknik penelitian dengan sample diwawancarai di dalam suatu cara atau perilaku responden yang diamati dan dijelaskan dalam beberapa cara (Zikmund et al., 2013). Metode analisis pada penelitian kali ini merupakan eksploratori kualitatif, dengan menggunakan metode tersebut maka untuk mendapatkan informasi yang valid berdasarkan data jenuh.

\section{HASIL}

Pada analisis menggunakan metode 7S McKinsey ini untuk mengidentifikasi apa yang diperlukan organisasi agar meningkatkan kinerja dan untuk mengimplementasikan strategi yang efektif pada multi dimensi pendekatan (Kaplan, 2005). Berikut merupakan penjabaran pada hasil analisis 7S McKinsey yang telah dilakukan oleh penulis.

\section{Values Form Culture}

Dengan shared values ini, peneliti ingin mengetahui nilai-nilai yang membentuk budaya dasar perusahaan dan dengan demikian dapat memengaruhi bagaimana orang berperilaku dalam organisasi, terutama dengan memengaruhi pola pikir. Pernyataan ini dibenarkan oleh kutipan wawancara kepada Direktur Utama PT HRBA.

\footnotetext{
“ [.....] sejauh ini saya memahami dari tujuan perusahaan maupun nilai-nilai yang dikemukakan oleh pemegang saham, yakni menjadi perusahaan fabrikasi dan coating yang terkemuka di Pulau Jawa. Nilai-nilai yang saya akan berikan kepada para staff sampai dengan manager yakni value of teamwork dan value of innovation [......] selain itu dengan adanya nilai kerja sama tim maka keputusan-keputusan yang diambil bertujuan untuk inovasi jasa yang akan kita kerjakan (Informan 3, Direktur Utama).
}

Berdasarkan kutipan wawancara komisaris utama dan direktur utama, kesimpulannya pada penggalan wawancara di atas nilai-nilai pada perusahaan ini yakni value of teamwork dan value of innovation. Tetapi dengan nilai utama tersebut maka semua departemen dan karyawan harus setuju dengan nilai-nilai yang dibangun oleh organisasi, oleh sebab itu nilai-nilai utama tersebut harus dipahami betul karena untuk masa depan perusahaan. Menurut peneliti, shared values perusahaan telah dibentuk sedemikian harus didokumentasikan secara jelas agar 
kesadaran atas nilai yang dibentuk oleh perusahaan dapat dijalankan sesuai dengan nilai-nilai yang menjadi core perusahaan.

\section{Low-Cost Strategy}

Dengan strategi, kita dapat merencanakan dalam menciptakan daya saing dan mencapai tujuan perusahaan.

\begin{abstract}
“Sebenarnya dengan kondisi saat ini strategi yang kami gunakan adalah memang sesuai ya dengan tipe perusahaan jasa saat ini mas, karena harga murah dalam pelelangan dapat memenangkan suatu proyek [....] permasalahannya dalam berjalannya waktu pekerjaan sering terjadi kendala yakni keterlambatan pekerjaan yang berimbas pada membengkaknya biaya yang harus dikeluarkan" (Informan 2, Komisaris).
\end{abstract}

Berdasarkan kutipan wawancara dengan komisaris dan direktur utama, PT Hasil Rotibua Abadi ini memang menggunakan low-cost strategy tetapi terdapat beberapa permasalahan dalam berjalannya strategi yang digunakan. Terjadinya permasalahan tersebut dikarenakan tidak ada GBHP (Garis Besar Haluan Perusahaan) yang mengakibatkan karyawan-karyawan belum menyadari betul penerapan strategi yang digunakan di perusahaan. Maka rekomendasi peneliti terhadap permasalahan ini adalah membuat GBHP (Garis Besar Haluan Perusahaan) terkait penerapan low-cost strategy dalam berjalannya perusahaan tetapi perusahaan juga harus membuat streamlined business process karena dengan adanya streamlined business process perusahaan dapat membuat metode bisnis proses yang akan dijalankan pada setiap proyek akan dikerjakan.

\section{Innovation}

Dengan adanya strategi pengembangan inovasi yang dikemukakan oleh pihak manajemen maka perusahaan menjalankan low cost strategy dengan inovasi-inovasi di setiap metode pekerjaannya. Berikut kutipan wawancara dengan direktur utama:

"[....] karena saat ini pemain-pemain di bidang fabrikasi dan coating ini sudah sangat jenuh, maka kami mewajibkan teman-teman di lapangan melakukan inovasi terkait dengan metode-metode pekerjaan yang akan kita lakukan" (Informan 3, Direktur Utama).

Berdasarkan wawancara dengan pihak direktur utama terlihat bahwa dengan adanya kombinasi low-cost strategy dengan inovasiinovasi yang dilakukan oleh pekerja di lapangan terkait dengan inovasi pada metode-metode pekerjaan yang dilakukan pada setiap proyekproyek. Peneliti berpendapat pada pemilihan kombinasi strategi ini sangat baik tetapi inovasiinovasi yang dilakukan pada metode pekerjaan jangan sampai memengaruhi jeleknya kebijakankebijakan K3 yang dibuat oleh Safety Officer PT HRBA.

\section{The Coercive and Authoritative Style}

Dengan style, peneliti bermaksud ingin mengetahui gaya kepemimpinan dalam perusahaan yang menjadi kunci perusahaan, berikut kutipan wawancara dengan project manager PT HRBA:

\footnotetext{
"Memang pada perusahaan ini kepemimpinan sangat perlu kepada pihak internal maupun eksternal. Internal di sini dari para direksi kepada saya maupun saya kepada para supervisor dan staffstaff terkait. [.....]. Di sini memang saya kepada para staff maupun supervisor saya menggunakan intuitif atas perintah saya" (Informan 4, Project Manager).
}

Berdasarkan kutipan wawancara yang dikemukakan oleh Project Manager PT HRBA, memang gaya leadership yang digunakan oleh project manager ini cocok untuk kondisi-kondisi 
di mana target harus direalisasikan sebelum due date proyek telah berakhir.

\section{Cross Learning Orientation}

Dengan Cross learning orientation, kepemimpinan manajer proyek dalam berjalannya suatu proyek dapat memberikan transfer ilmu kepada staff-nya, berikut kutipan wawancara dengan Project Manager PT HRBA.

"Dalam berjalannya suatu proses pekerjaan, biasanya saya berikan mereka ilmu yang tidak mereka dapatkan sebelumnya seperti bagaimana membuat kurva s yang baik dan benar maupun sampai dengan perancangan anggaran proyek yang dikerjakan" (Informan 4, Manajer Proyek).

Berdasarkan kutipan wawancara dengan manajer proyek, pada berjalannya perusahaan sering kali manajer proyek ini menggunakan cara transfer ilmu kepada staff-staff nya untuk meningkatkan kompetensi karyawan dimana dengan adanya transfer ilmu yang diberikan maka kerja manajer proyek akan semakin mudah dan staff-staff mudah dikontrol oleh manajer proyek.

\section{Cross Functional Information}

Dalam berjalannya suatu organisasi, sistem dapat memengaruhi berbagai hal yang menyangkut aktivitas perusahaan sehari-hari hingga perencanaan, implementasi, kontrol, penyampaian informasi, evaluasi, anggaran, dan penghargaan. Berikut kutipan wawancara dengan komisaris utama terkait dengan sistematika perusahaan yang berada di PT Hasil Rotibua Abadi.

"Sistematika perusahaan yang dibuat berdasarkan tujuan perusahaan yakni cross functional information, hingga mencapai produktivitas karyawan, tetapi belum terlalu efektif dan efisien dalam berjalannya perusahaan. [.....]" (Informan 1, Komisaris Utama).
Berdasarkan kutipan wawancara dengan komisaris utama, sistem perusahaan yang digunakan memang sudah berjalan yakni tetapi belum berjalan efektif dan efisien.

\section{Cross Functional Training and Coaching}

Dengan adanya cross functional training and coaching pada perusahaan, maka seluruh elemen perusahaan dari direktur hingga staff dari berbagai divisi dapat merasakan berbagai pelatihan yang diadakan dari pemilik proyek yakni pihak BUMN maupun yang PT HRBA adakan. Berikut kutipan wawancara dengan pihak manajer proyek.

"Untuk pelatihan-pelatihan biasanya ketika pihak PT Petrokimia Gresik mengadakan pelatihan untuk pengembangan dasar-dasar K3 maka perusahaan kami mengirimkan perwakilan dari PT HRBA untuk mengikuti pelatihan tersebut, tidak serta merta kami kirimkan dari divisi HSE (health safety and environment) saja tetapi dari engineering kami sertakan untuk turut serta dalam pelatihan. Dari pelatihan yang diadakan untuk internal perusahaan kami adakan pelatihan pengembangan $\mathrm{K} 3$ untuk para supervisi lapangan, maupun pelatihan tentang pengenalan proses pekerjaan yakni coating dan fabrikasi untuk diikuti para safety officer kami” (Informan 4. Manajer Proyek).

Berdasarkan kutipan wawancara dengan manajer proyek, sistem perusahaan dengan menggunakan cross functional training and coach ini membuat efisiensi perusahaan dalam biaya yang dikeluarkan lebih efektif dengan mengikuti pelatihan yang diadakan oleh pihak user. Dalam internal perusahaan pun, transfer ilmu yang diberikan kepada para staff terbukti efektif dan dapat meningkatkan kompetensi karyawan.

\section{Cross Functional Jobs}

Struktur organisasi adalah fondasi bisnis untuk membuat eksistensi yang berkelanjutan 
dari kompetisi suatu pasar. Berikut merupakan kutipan wawancara pada direktur utama:

\begin{abstract}
"Memang kita sudah buat struktur organisasi secara terperinci tetapi pada kenyataannya pada suatu pekerjaan yakni project manager yang membawahi seluruh supervisor maupun staff semua divisi dalam hal pelaporan-pelaporan progress pekerjaan, kontrol proyek, pembuatan rancangan biaya proyek, hingga ke material yang digunakan. Tetapi apabila suatu proyek yang jangkauannya jauh dan hanya cukup di-handle oleh supervisi saja maka pelaporan kutipan atau pelaporan pekerjaan maupun kontrol proyek menjadi tanggung jawabnya” (Informan 3, Direktur Utama).
\end{abstract}

Berdasarkan kutipan wawancara kutipan direktur utama bahwa struktur organisasi yang dibentuk memang sudah terperinci tetapi fleksibilitas aktivitas yang paling terpenting dikarenakan apabila terjadi penyampaian informasi yang diberikan harus melalui manajer proyek lalu ke direktur butuh waktu maka supervisi dapat langsung menyampaikan permasalahan-permasalahan yang genting kepada direktur, setelah itu dikomunikasikan kepada manager agar dirapatkan bersama.

\section{Certified Skill}

Yang dimaksud dengan skills pada metode 7S Mckinsey merupakan kompetensi karyawan yang bekerja untuk perusahaan, merupakan unsur yang sangat penting bagi keberhasilan organisasi dalam mencapai sasaran dan tujuannya dengan efektif dan efisien (Bingham, Eisenhardt, \& Furr, 2009). Hal ini juga dikemukakan berbeda oleh manajer proyek PT Hasil Rotibua Abadi, berikut kutipan wawancaranya.

"Untuk kompetensi skill karyawan di perusahaan saya rasa cukup dengan adanya coating inspector, welding inspector, maupun safety officer, dikarenakan berjalannya perusahaan berdasarkan proyek dan biasanya dalam suatu proses admi- nistrasi pelelangan harus disertakan sertifikat keahlian-keahlian tersebut. Untuk kompetensi yang lain seperti drawing, project controlling dengan kurva s, maupun estimasi pekerjaan didapatkan dari transfer ilmu yang diberikan langsung oleh saya maupun direktur utama."

Berdasarkan kutipan wawancara dengan manajer proyek, dapat disimpulkan bahwa untuk kompetensi dari skill karyawan PT Hasil Rotibua Abadi saat ini sudah cukup baik, kompetensi karyawan dalam perhitungan anggaran proyek, kontrol proyek, maupun menggambar teknik sendiri memang saat ini hanya berdasarkan transfer ilmu yang diberikan langsung oleh direktur utama. Namun ada beberapa kompetensi yang harus disertakan dalam dokumen administrasi pelelangan yakni coating inspector, welding inspector, maupun safety officer. Hal ini yang menyebabkan perusahaan harus memperbarui kompetensi skill dari karyawannya.

\section{Certified Staff}

Berdasarkan tujuan perusahaan yang sudah dikemukakan, maka suatu organisasi harus mempunyai personel staff yang sesuai dengan proses bisnis perusahaan. Berikut kutipan wawancara kepada direktur utama terkait staff yang ada di perusahaan.

"Staff yang berada di perusahaan kami memang
saat ini sudah cukup dengan berjalannya proses
bisnis perusahaan dengan adanya kompetensi-
kompetensi yang dimiliki oleh karyawan perusa-
haan, [.....] tetapi apabila dalam suatu tender
mengharuskan adanya staff safety officer dan staff
coating inspector, otomatis kami harus merekrut
karyawan-karyawan yang memiliki sertifikasi ter-
sebut. Biasanya kami merekrut karyawan yang
bersertifikasi berdasarkan rekomendasi-rekomen-
dasi dari asosiasi member seperti contoh Ascoatin-
do (Asosiasi Coating Indonesia). [....] Pengem-
bangan staff perusahaan biasanya pasti kita laku-
kan pelatihan-pelatihan bersertifikasi BNSP, tetapi
sebelum itu biasanya kita lakukan seleksi inter- 
nal berupa uji kompetensi di lapangan terkait dengan spesifikasi pekerjaan" (Informan 3, Direktur Utama).

Berdasarkan kutipan wawancara terhadap direktur utama bahwa saat ini perusahaan sudah memiliki staff yang cukup tetapi tidak menutup kemungkinan apabila user mengharuskan adanya safety officer maupun coating inspector yang menetap di suatu lokasi proyek maka perusahaan tetap merekrut karyawan baru yang sesuai dengan kompetensi sertifikasi tersebut.

\section{KESIMPULAN}

Berdasarkan hasil analisis dan pembahasan yang telah dipaparkan, dapat disimpulkan bahwa strategi PT HRBA dalam berjalannya proses bisnisnya memang menggunakan low-cost leadership dan innovation, dengan strategi fundamental PT HRBA sudah sangat baik tetapi pemaparan strategi pada aktivitas perusahaan tersebut belum dipahami oleh pihak karyawan-karyawan. Shared values PT HRBA pada budaya yang diterapkan di perusahaan berasal dari dibentuknya nilai-nilai perusahaan, pada hakikatnya nilai yang membentuk budaya yakni values of teamwork dan values of innovation. Pada values of teamwork ini dapat meningkatkan kualitas sumber daya manusia perusahaan maupun efektivitas operasional perusahaan, untuk values of innovation ini perusahaan harus mendorong terobosanterobosan yang diperlukan untuk meningkatkan kapabilitas dan kompetitif perusahaan dari para karyawan hingga level direksi. Style atau gaya kepemimpinan perusahaan dalam berjalan aktivitas bisnisnya masih kurang efektif dikarenakan kepemimpinan yang diterapkan oleh perusahaan lebih intuitif daripada menemani karyawan yang bersangkutan dalam rangka ikut serta dalam pengambilan keputusan. Sistem yang diterapkan perusahaan saat ini mencoba dengan penerapan cross-functional information, di mana informasiinformasi terkait dengan satu divisi dengan divisi lain sangat dibutuhkan untuk mengetahui informasi-informasi terkini terkait dengan proses bisnis perusahaan. Structure pada penggunaan crossfunctional jobs ini PT HRBA memang saat ini belum berjalan efektif dikarenakan kurangnya sumber daya manusia yang melingkupi proses bisnis perusahaan. Skill kompetensi yang berbasis pada sertifikasi-sertifikasi yang dimiliki oleh karyawan PT HRBA, dapat mendukung proses bisnis perusahaan tetapi saat ini yang memiliki kompetensi berdasarkan sertifikasi dari pemerintah saat ini hanya ada 4 staff dari total 50 karyawan perusahaan. Staff yang dimiliki oleh PT HRBA saat ini $60 \%$ berada pada usia 50-60 tahun dan semua nya tidak memiliki kompetensi yang tersertifikasi oleh asosiasi bidang pekerjaan yang PT HRBA geluti saat ini, maka diperlukan nya regenerasi staff dengan pengalaman yang cukup dan memiliki sertifikasi dari asosiasi bidang pekerjaan yang dijalani oleh PT HRBA. Meskipun cost yang timbul sangat besar tetapi dampak positif dalam berjalannya organisasi akan sesuai dengan keinginan pemilik perusahaan.

\section{REFERENSI}

Babin, B.J. \& Zikmund, W.G. 2013. Essentials of Marketing Research. Nelson Education. Brent, D. Ruben \& Lea P. Stewart. 2013. Komunikasi dan Perilaku Manusia. Jakarta: Raja Grafindo Persada.

Bengtsso, T. \& O. Saito. 2004. Population and Economy: From Hunger to Modern Economic Growth. Oxford University Press.

David, Fred R. 2011. Manajemen Strategis: Konsep-Konsep, Edisi Dua Belas. Jakarta: Salemba Empat. 
Ebeling, Charles E. 2010. An Introduction to Reliability and Maintainability Engineering. Long Grove, Il, Waveland Press INC.

Guenzi, P. \& Storbacka, K. 2015. The Organizational Implications of Implementing Key Account Management: A Case-Based Examination. Industrial Marketing Management, 45, 84-97.

Hadiansyah, H., Purwandari, B., Satria, R., \& Yudhoatmojo, S.B. 2018 Social Media Strategies for Public Diplomacy: A Case Study in the Ministry of Foreign Affairs of the Republic of Indonesia. In Informatics and Computing (ICIC), 2017 Second International Conference on (pp. 15). IEEE.

Kotler, Philip \& Keller. 2012. Marketing Management, Global Edition. Pearson Prestice Hall.

Mintzberg, H. 2001. The Strategy Concept I: Five Ps for strategy. California Management Review, 30(1), 11-24.

Patton Jr, J.D., Business, M.I.B., \& Best, N.N.I. 2006. Maintenance, Long-Term Support and System Management. A Guide to the Automation Body of Knowledge, 421.
Porter, M.E. \& Kramer, M.R. 2006. The Link between Competitive Advantage and Corporate Social Responsibility. Harvard Business Review, 84(12), 78-92.

Porter, M.E. \& Kramer, M.R. 2006. The Link between Competitive Advantage and Corporate Social Responsibility. Harvard Business Review, 84(12), 78-92.

Porter, M.E. 2008. The Five Competitive Forces that Shape Strategy. Harvard Business Review, 86(1), 78-93.

Scheffer, C. \& Girdhar, P. 2004. Practical Machinery Vibration Analysis and Predictive Maintenance. Elsevier.

Singh, A. 2013. A Study of Role of McKinsey's $7 \mathrm{~S}$ framework in Achieving Organizational Excellence. Organization Development Journal, 31(3), 39.

Tampubolon, M.P. 2004. Manajemen Operasional, 98. Jakarta: Ghalia Indonesia.

Wheelen, T.L. \& Hunger, J. 2006. David-Strategic Management and Business Policy: Concepts and Cases.

Zikmund. 2013. Business Research Methods, Ninth Edition. South Western. 